\title{
Is Knowledge of Semantic Macro-Structure Effective on Writing Performance of Iranian EFL Students?
}

\author{
Hadiseh Esmaeeli (Corresponding Author) \\ Department of Language and Literature, Larestan Branch \\ Islamic Azad University, Larestan, Iran \\ E-mail: yas.yas2100@gmail.com \\ Afshin Soori \\ Department of Language and Literature, Larestan Branch \\ Islamic Azad University, Larestan, Iran \\ E-mail: Afshin_soori@yahoo.com
}

Received: 24-03-2014

doi:10.7575/aiac.ijalel.v.3n.6p.139
Accepted: 15-07-2014

Published: 01-11-2014

\begin{abstract}
This study set out to investigate whether the knowledge of semantic macro-structures on the report writing of Iranian EFL students in terms of three main categories of rating, namely structure, vocabulary, and organization. This study is a true experimental design which provides pretest of general proficiency test as well as pretest of writing ability. It also involves treatment program for the experimental group and placebo for the control group and finally a posttest of writing. The participants of this study were 40 male upper-intermediate Iranian EFL students studying English in two well-known English institutes of Jahrom. Having used t-test, the researcher found that there was no significant difference between the subjects' reports vocabulary, structure, and organization quality across groups of control and experimental.
\end{abstract}

Keywords: Macrostructure, Macro rules, Semantic macro structure

\section{Introduction}

Language users assign meanings to text in processes of interpretation and the meanings are derived from the local meaning of words and sentences. According to Van Dijk (1985) this derivation takes place by using a set of macro-rules whereby the propositional content across several utterances may be summarized and formulated as macropropositions. When using macro rules, the focus is still on the meaning of words and sentences in the text - units that form patterns of coherence. According to Van Dijk (1985), we must specify how meanings of consequent sentences are related, and how facts these sentences refer to are related in order to describe the notion of coherence.

Besides the meanings of words and sentences, world knowledge (extra linguistic knowledge) affects the reader's ability to understand a piece of text as a coherent whole. Conditions, causes, or reasons may be involved in these links between sentences, and these presuppose the writer's knowledge or beliefs about how events or situations in the world (outside the text) are organized (Van Dijk 1985). For instance, the very simple word 'because' may indicate a large set of assumptions about the social or political world the text refers to. As already stated, an understanding of how language is used in the text is a prerequisite for identifying, extracting and representing the meaning. This understanding can be achieved by a close study of the situations and activities where words and phrases are/were used.

Obviously, the world knowledge or beliefs may be different for writer and reader, and therefore Van Dijk (1985) argues that local coherence also may be subjective: Propositions may cohere for the writer but not for the reader. This theory of coherence has clear implications for the text analytical approaches since the writer presupposes vast amounts of social and political knowledge.

A researcher will not necessarily share the common ground of the writer and the text's intended readers. Since text is abstracted out of its real-life situation, the researcher may find it difficult to perceive the propositions as coherent. As Werth (1999) puts it:

"Rather than being based on propositional links in the text, it is based on propositional links between the text and Common Ground, ..., is all the information necessary to interpret the discourse..." (1999, p. 127).

Van Dijk's (1985) theory of macro propositions derived from using a set of macro rules and how the macro propositions are organized in macrostructures can be used as guidelines when documenting the relevance judgments made during text analysis and interpretation. "Macrostructures have a cognitive nature. Macrostructures have a subjective nature since different language users may find different information in the text more important." (Van Dijk 1985, p.33). 
A macrostructure is basically a semantic construction used to organize the macro propositions according to some criteria. For instance, these criteria can reflect argumentative features, for example language features referring to pragmatic arguments, ethical arguments, or moral arguments.

Macro rules are semantic mapping rules or transformations, which link lower level propositions with higher level macro propositions. The rules are basically simple techniques aiming at data reduction and are applied iteratively and recursively. They are applied in a qualitative approach in which the expressed opinions are interpreted in a textual context, classified and organized according to the theoretical framework presented in the research project at hand.

\section{Statement of the Problem}

As already mentioned elsewhere in this study, the problem addressed in this study is based on the assumption that although one can witness work on cognitive, social and motivational factors in task based teaching (Fraser, 1991; Pintrich \& Schunk, 2002), as well as an attention to the difference between language and other school subjects (Gardner, 1985), one should not forget the distinction between spoken and written discourse. Tannen (1982), for example, suggests that such distinction is related to genre and register, whereas Ure (1971) suggested that lexical density variation is the distinctive feature between the spoken and written form of language. In line with this specification, Van Dijk (1985) proposed a set of macrorules for written discourse which contribute to the interpretation of the given written text. In fact, Macrorules are semantic mapping rules or transformations, which link lower level propositions with higher level macropropositions. The rules are basically simple techniques aiming at data reduction and are applied iteratively and recursively. They are applied in a qualitative approach in which the expressed opinions are interpreted in a textual context, classified and organized according to the theoretical framework presented in the research project at hand.

\section{Significance of the Study}

A macrostructure is a theoretical reconstruction of intuitive notions such as topic or theme of a discourse. It explains what is most relevant, important, or prominent in the semantic information of the discourse as a whole. At the same time, the macrostructure of a discourse defines its global coherence. Without such a global coherence, there would be no overall control upon appropriately according to the given local coherence criteria, but the sequence would simply go astray without some constraint on what it should be about globally.

The above facts may be related locally, but they are not related to one central issue or topic. The macrostructure is the semantic information that provides this overall unity to a discourse. Often such underlying macrostructures are expressed by the text itself, for example, in announcements, titles, summaries, thematic sentences, or the expression of plans for action.

According to the fundamental principle of semantics, a macrostructure of a discourse should be a function of the respective meanings of its sentences. This function, however, is not given by an added connectivity at the local level of the sequence, that is, the sum of all pair wise coherence links between sentences. Rather it is a kind of semantic transformation, mapping sequences of propositions of the text on sequences of macro propositions at more abstract, general, or global levels of meaning. Intuitively, such mappings are operations that select, reduce, generalize, and reconstruct propositions into fewer, more general, or more abstract propositions. These transformations or operations are called macro rules. They are second-order semantic interpretation rules: After the interpretation of sentences and sentence pairs, they allow a further interpretation of sequences as (global) propositions that characterize the meaning of a sequence or discourse as a whole. In line with the aim of the study, the researcher presents the following research question:

1. Does semantic macro-structure improve the students' news text report writing?

2. Does semantic macro-structure have a significant effect on structure and usage ability of the students' news text report writing?

3. Does semantic macro-structure of the news texts have a significant effect on the organization ability of the students' news text report writing?

4. Does semantic macro-structure of the news texts have a significant impact on vocabulary ability of the students' news text report writing?

\section{Literature Review}

Texts have structures at higher more complex levels than sentence units (Garcia-Berrio, 1988). Language users assign meanings to text in processes of interpretation and the meanings are derived from the local meaning of words and sentences. According to van Dijk (1980) this derivation takes place by using a set of macrorules whereby the propositional content across several utterances may be summarized and formulated as macropropositions. When using macrorules, the focus is still on the meaning of words and sentences in the text - units that form patterns of coherence. According to van Dijk (1980), we must specify how meanings of consequent sentences are related, and how facts these sentences refer to are related in order to describe the notion of coherence.

Besides the meanings of words and sentences, world knowledge (extralinguistic knowledge) affects the reader's ability to understand a piece of text as a coherent whole. Conditions, causes, or reasons may be involved in these links between sentences, and these presuppose the writer's knowledge or beliefs about how events or situations in the world (outside the text) are organised (van Dijk 1980). For instance, the very simple word 'because' may indicate a large set of assumptions about the social or political world the text refers to. As already stated, an understanding of how language is 
used in the text is a prerequisite for identifying, extracting and representing the meaning. This understanding can be achieved by a close study of the situations and activities where words and phrases are/were used.

Obviously, the world knowledge or beliefs may be different for writer and reader, and therefore van Dijk argues that local coherence also may be subjective. This means that propositions may cohere for the writer but not for the reader. This theory of coherence has clear implications for the text analytical approaches since the writer presupposes vast amounts of social and political knowledge. Werth (1999) postulates that coherence is not inherent in text, rather the reader of the text constructs coherence. In order for the writer and reader to share a common perception of coherence, the writer and reader have to share some common ground of knowledge, where common ground is defined as: "...the totality of information which the speaker(s) and hearer(s) have agreed to accept as relevant for their discourse." (1999, p.125).

A researcher will not necessarily share the common ground of the writer and the text's intended readers. Since text is abstracted out of its real-life situation, the researcher may find it difficult to perceive the propositions as coherent. As Werth (1999, p. 127) puts it, "rather than being based on propositional links in the text, it is based on propositional links between the text and common ground, ..., is all the information necessary to interpret the discourse...". In other words, evoked knowledge as well as stated propositions enter into coherence relationships and thereby influence the understanding and interpretations made. This leads to the notion of relevance. What is perceived as relevant changes when propositions evokes knowledge - a text, after reading some propositions, may be considered as relevant, but after reading more propositions, changes into a state of 'somewhat relevant', and further into non-relevant. Relevance is not a static phenomenon, but evolves and changes during reading and interpretation. A text becomes more specific in the reader's mind for each new proposition added, and this leads to the crucial question - what set of propositions should the relevance judgment be based on?

Van Dijk's theory of macropropositions derived from using a set of macrorules and how the macropropositions are organised in macrostructures can be used as guidelines when documenting the relevance judgments made during text analysis and interpretation.

"Macrostructures have a cognitive nature. Macrostructures have a subjective nature since different language users may find different information in the text more important." (van Dijk 1988,p. 33).

A macrostructure is basically a semantic construction used to organize the macropropositions according to some criteria. For instance, these criteria can reflect argumentative features, for example language features referring to pragmatic arguments, ethical arguments, or moral arguments.

Since the idea of pragmatic macro-structures has been formed in analogy with macro-structures on the semantic level of discourse description, we should first briefly resume what we understand by such semantic macro-structures, especially since the cognitive basis for both is probably identical (Van Dijk, 1980).

According to Van Dijk (1980), it is assumed that the meaning of a discourse should be characterized at two levels, viz. that of the sentences and their linear, pair wise connections on the one hand, and that of the discourse, or fragments of it, taken as a whole, on the other hand. These accounts thus differentiate between a local or micro-level and a global or macro-level of analysis. There are several linguistic, semiotic and cognitive reasons for this theoretical distinction. First of all, semantic macro-structures make explicit the important intuitive notion of topic of discourse. In fact, they specify what a discourse, as a whole, is about, in a non-trivial way, i.e. not by a simple enumeration of the meanings of its respective sentences. Thus, I may tell a story about John is travelling to Ghent, even if this particular proposition is not expressed in my story.

Apart from its independent motivation in a theory of communication, the topic of discourse is also needed in the explication of linear coherence between sentences of a discourse. In fact, two sentences may be said to be connected only relative to such a topic of discourse or conversation.

According to Van Dijk (1980), macro-structures are to be postulated in the account of a number of linguistic phenomena, such as the use of definite noun phrases without textually expressed particular antecedents. Macrostructures are further required in order to make explicit the semantic relations between a discourse and its (possible) summaries. Thus, it is assumed that a summary is a verbal expression of a macro-structure of the discourse it summarizes.

At the cognitive level, Van Dijk (1980) argues that macro-structures are introduced as a necessary component in complex information processing. In order to be able to plan, execute, control discourse in production, and to understand, store, retrieve and reproduce discourse, a macro-level of processing must be postulated. A normal language user is unable to store and retrieve all individual sentences (propositions) of a discourse, and yet understands the discourse as a coherent whole, being able to recall and summarize it without necessarily having access to the individual propositions. Thus, during input, a reader will on the basis of the interpretation of the respective sentences of the discourse, construct a (set of) macro-structures, which organize and reduce the highly complex information to a manageable size, being the schema on which processing (storage, recall, etc.) is based (Van Dijk and Kintsch, 1983).

In another framework of discourse description, e.g. at the more general semiotic or, more in particular rhetorical, levels, macro-structures of discourse are the basis for specific constraints from other systems. Thus, narrative structures may be mapped onto a discourse, thus assigning specific narrative functions to parts of the discourse, e.g. Setting, Complication, Resolution, Moral, etc. These narrative categories, however, do not map onto individual 
sentences/propositions, but onto macro-structures of the discourse. The complication of a story may for instance be expressed by a whole sequence, e.g. several paragraphs or a chapter, of the story, of which the global semantic coherence is defined in terms of macro-structure.

Being a semantic notion, macro-structures are also characterized in terms of propositions or conceptual networks of the usual kind (Garcia-Berrio, 1988). The difference with those of sentences is one of level. That is, macro-structures are obtained by semantic mappings (transformations) applied to the local, sentential meanings of the discourse. These mappings are called macro-rules. The different kinds of macro-rules generalize, delete and construct with respect to those sentential meanings.

At the formal, theoretical level, they represent the cognitive processes/operations of information reduction mentioned above. A typical example is given by a discourse (fragment) in which we read about the different details of house building: we map the respective sentences onto the macro-proposition $\mathrm{A}$ is building a house, representing our global understanding of that passage.

\section{Design of the Study}

Experimental design is the blue print of the procedures that enable the researcher to test hypotheses by reaching valid conclusions about relationships between independent and dependent variables. In fact, selection of a particular design is based on the purpose(s) of the study. Moreover, the design tells us how the variables are controlled or manipulated and how the subjects are to be assigned to the experimental and control groups. There are three types of experimental designs (Best and Kahn, 2006). This study is true experimental design which provides pretest of general proficiency test as well as pretest of writing ability.

\section{Participants}

The location of this study was in Jahrom, Iran and the students of two English institutes were selected as the participants of the study. At first they were 60 and they were all studying at the advanced level in the institutes. Having run initial tests, only 40 subjects were selected and placed into two groups of experienced and control. Age was not a variable and all the subjects were males.

\section{Instruments}

To test the hypothesis, namely the subjects' knowledge of the news semantic macro-structure does not have a significant effect on developing their task based writing; the researcher used the following instruments to collect data:

- $\quad$ General proficiency test: In order to select a specific homogenous sample of subjects, the researcher selected a general test of proficiency to administer as the first tool of the study. The test contained three parts of structure and written expression, reading comprehension, and vocabulary. It contained 80 questions and the subjects were given 80 minutes to complete the test. It is pressing to note that only those subjects with 1 standard deviation over the mean were selected to participate in the study.

- Writing task (pre-test): since purpose of the research was specifically aimed at writing in a task-based environment, the pre-test of writing was designed likewise, concentrating on the news texts. The researcher used a sample of news texts including major current headlines and the subjects were asked to write a report about each news texts. Five news texts were selected and five reports were collected from each subject.

- $\quad$ Post-test writing: this test was design to evaluate the result of the treatment or program and compare it to the control group. It involved writing reports about some major current news texts selected from Tehran Times. For the purpose of this study, 5 news texts were selected and were presented as the post-tests. The subjects were asked to provide a summary of each text in line with the content of the sessions they had participated during the period of 16 sessions. A sample of the news texts and the subjects' reports are recorded in appendix

\section{Data Analysis}

Having rated the pre-test, the researcher ran a preliminary t-test in order to see if the mean scores of both control and experimental groups belonged to the same population. In other words, the researcher tried to find if there was any significant difference among the subjects' report writing performance prior to the program (Table 1)

Table 1. t-test for pretest

\begin{tabular}{|c|c|c|c|c|c|c|c|c|}
\hline \multicolumn{5}{|c|}{ Paired Differences } & $\mathrm{t}$ & $\mathrm{df}$ & \multicolumn{2}{|c|}{ Sig. (2-tailed) } \\
\hline Mean & Std. Deviation & $\begin{array}{l}\text { Std. Error } \\
\text { Mean }\end{array}$ & $\begin{array}{r}95 \% \\
\text { Inter } \\
\text { Di }\end{array}$ & $\begin{array}{l}\text { onfidence } \\
\text { al of the } \\
\text { erence }\end{array}$ & Mean & $\begin{array}{c}\text { Std. } \\
\text { Deviation }\end{array}$ & \multicolumn{2}{|c|}{ Std. Error Mean } \\
\hline \multirow[t]{2}{*}{ Lower } & Upper & Lower & Upper & Lower & Upper & Lower & Upper & \\
\hline & .06667 & .90719 & .16563 & -.27208 & .40542 & .403 & 29 & .690 \\
\hline
\end{tabular}

As observed from the analysis, the lower and the upper limits include 0 . In other words, there was no significant difference between the control group and experimental group with respect to their performance on pretest. After the treatment program, the researcher carried out three separate t-tests for sentence structure, organization, and vocabulary 


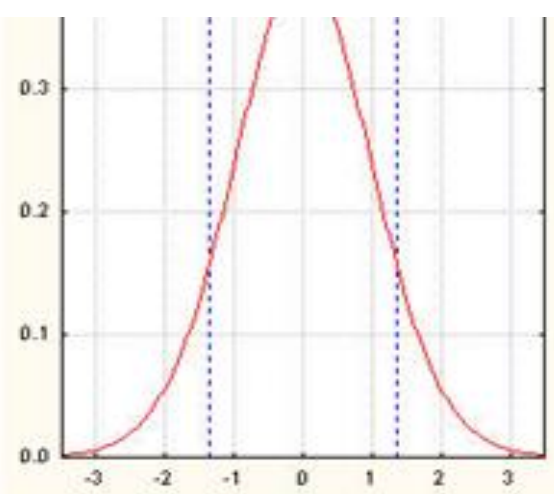

esearcher investigated the effect of knowledge of semantic macro structure on to structure section of the rating (Table 2).

:e structure section of the rating scale.

\begin{tabular}{llll}
\hline St. Dev. & SE Mean & T & Sig. level(2-tailed) \\
\hline 1.19 & .27 & 1.37 & .18 \\
\hline 1.23 & .25 & & \\
\hline
\end{tabular}

The obtained value failed to exceed .05 level of significance; hence, the researcher failed to reject the first null hypothesis, therefore, no significant difference was found between control and experimental groups with respect to sentence structure section of the ratings. In other words, knowledge of semantic macro-structures did not have any significant effect on the sentence-structure quality of the news text report writing. Next, the researcher addressed the organization section of the rating. (Table 3)

Table 3. Two sample t-test for the organization section of the rating scale.

\begin{tabular}{llllll}
\hline $\mathrm{N}$ & Mean & St. Dev. & SE Mean & $\mathrm{T}$ & Sig. level(2-tailed) \\
\hline 20 (exp.) & 16.55 & 1.93 & .43 & 3.69 & .001 \\
\hline 20 (cont.) & 14.2 & 2.09 & .47 & & \\
\hline
\end{tabular}

The obtained value, .001 is lower than .05 level of significance. Hence, the researcher rejected the second null hypothesis; therefore, there was a significant difference between control and experimental groups with respect to the organization section of the ratings. In other words, knowledge of semantic macro-structures had a significantly positive effect on the organizational quality of the news text report writing. Figure1 graphically presents the areas of probability of the rejection of the hypothesis for this particular section of the rating.

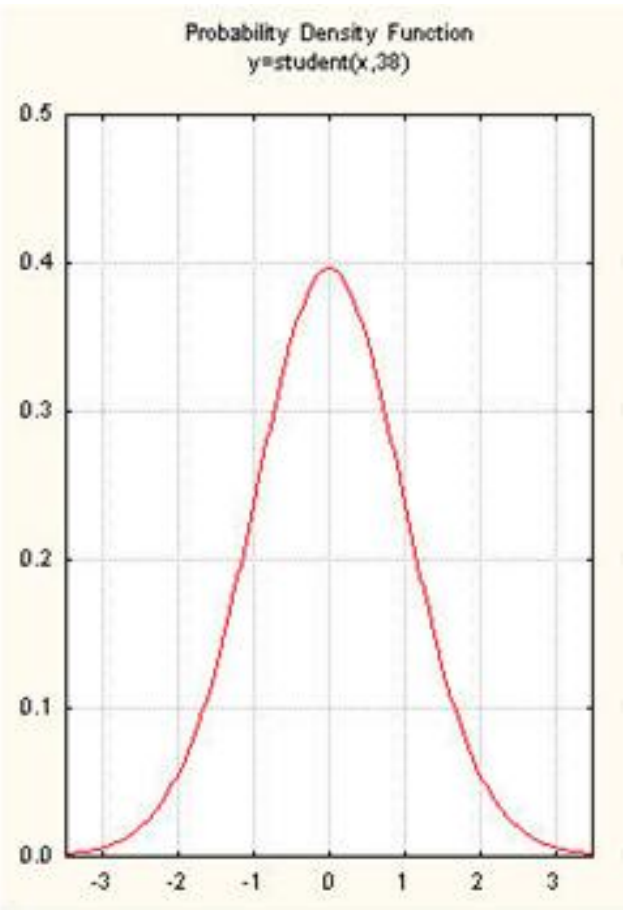

Figure1. Probability density function

Finally, the researcher addressed the vocabulary section of the rating in which the results are shown in Table 4. 
Table 4. Two sample t-test for the vocabulary section of the rating scale.

\begin{tabular}{llllll}
\hline $\mathrm{N}$ & Mean & St. Dev. & SE Mean & $\mathrm{T}$ & Sig. level(2-tailed) \\
\hline 20 (exp.) & 16.9 & 1.62 & .36 & 3.2 & .003 \\
\hline 20 (cont.) & 15.5 & 1.1 & .25 & & \\
\hline
\end{tabular}

The obtained value, .003 is lower than .05 level of significance. Hence, the researcher rejected the third null hypothesis; therefore, there was a significant difference between control and experimental groups with respect to the vocabulary section of the ratings. In other words, the knowledge of semantic macro-structures had a significantly positive effect on this quality of the news text report writing. Figure 1 graphically presents the areas of probability of the rejection of the hypothesis for this particular section of the rating.

Having tested all null hypotheses using t-test, the researcher concluded that the knowledge of semantic macro structure of the new texts had positively significant effect on the quality of vocabulary and organization of the subjects' reports of the news texts; nevertheless, such knowledge had no significant effect on the quality of structure of the subjects' reports on the news texts.

\section{Findings \& Conclusion}

Having administered selected subjects by administering the pretest and making sure that they belong to the same population regarding their performance on report writing of news texts, the researcher ran the treatment program during which the subjects in experimental group were taught how to analyze and interpret the news texts according to macro rules. They were also given assignments and other related activities. Nevertheless, the subjects in the control group were simply taught general report writing techniques reflected in study skill materials.

Having administered the posttest which contained five news texts for which the subjects in control and experimental groups were asked to write their reports. Next, the researcher asked five raters to rate the papers in terms of structure, organization, and vocabulary. Next, using t-test for each category, the researcher tested three hypotheses he considered earlier. He found that as far as the structure section is concerned, there was no significant difference between the subjects in control and experimental groups. However, the subjects in control and experimental groups were significantly different in terms of organization and vocabulary sections of their report ratings. In fact, the subjects in the experimental group were found to be significantly higher than subjects in control group. In other words, the knowledge of semantic macro-rules of news text had significantly positive effect on the improvement of the vocabulary and organization sections of their ratings.

\section{References}

Best, J.W and Kahn, J.V. (2006). Research in Education. Pearson. Aylin and Bacon.

Fraser, B. J. (1991). Two decades of classroom environment research. In B. J. Fraser \& H. J. Walberg (Eds.), Educational environments: Evaluation, antecedents and consequences (pp. 3-27). Oxford: Pergamon Press.

Pintrich, P. R., \& Schunk, D. H. (2002). Motivation in education: Theory, research, and applications (2nd ed.). Upper Saddle River, NJ: Merrill Prentice Hall.

Tannen, D. (1982). Spoken and written language. Norwood, NJ: Abblex

Ure, J. (1971). Lexical density and register differentiation. In Trim (ed.) Applications of linguistics. Cambridge.

Cambridge University Press.

Van Dijk, T. (1985). Handbook of discourse analysis. London. Academic Press

Werth, P. (1999). Text Worlds: Representing Conceptual Space in Discourse. New York: Longman. 